\title{
Synthesis, Characterization, Identification and Quantification of Sertraline Hydrochloride Related Impurities
}

Ajit Anerao*, Vihar Telange, Nitin Bondre, Satish John, Vikram Dighe, Rajendra Jagushte and Nitin Pradhan

R\&D Centre (API), Wanbury Ltd., Mahape, Navi Mumbai, Maharashtra, India

\begin{abstract}
Sertraline hydrochloride is an antidepressant of the selective serotonin reuptake inhibitor (SSRI) class, is synthesized for commercial use as a drug substance in highly pure form. During the synthetic process development studies of Sertraline hydrochloride, an impurity was detected in the final product at levels ranging from $0.05 \%$ to $0.15 \%$ in Gas Chromatography (GC) method and its molecular weight was determined by LC-MS analysis. The impurity was identified as 4-(4-chlorophenyl)-3,4-dihydronaphthalen-1(2H)-ol impurity, synthesized and characterized, the process of its formation was discussed in detail. After qualification of impurity standard, it was used as a reference standard for development of quantification by High Performance Liquid Chromatography (HPLC) method.
\end{abstract}

Keywords: Sertraline hydrochloride; Method development; Isolation; Characterization; LC-MS; NMR; HPLC

\section{Introduction}

Sertraline is chemically known as (1S,4S)-4-(3,4-dichlorophenyl)$\mathrm{N}$-methyl-1,2,3,4-tetrahydronaphthalen-1-amine. Sertraline, having a chemical structure as shown in Figure 1, has a molecular weight of 306.229 and its molecular formula is $\mathrm{C}_{17} \mathrm{H}_{17} \mathrm{C}_{12} \mathrm{~N}$.

Sertraline (trade names Zoloft and others) is an antidepressant of the selective serotonin reuptake inhibitor (SSRI) class [1,2]. It was introduced to the market by Pfizer in 1991. Sertraline is primarily prescribed for major depressive disorder in adult outpatients as well as obsessive-compulsive disorder, panic disorder, and social anxiety disorder, in both adults and children [3-5]. In 2013, it was the most prescribed antidepressant and second most prescribed psychiatric medication (after alprazolam) on the US retail market, with over 41 million prescriptions [6].

Sertraline hydrochloride drug substance is official in United State pharmacopoeia (USP) [7] as well as European Pharmacopoeia (EP) [8]. The listed organic impurities and method of analysis by gas chromatography is same in both pharmacopoeias. In most of the commercial batches one unknown impurity is observed at relative retention time (RRT) 0.66 is about $0.05 \%$ to $0.15 \%$ (Figure 2). Here in this research article attempts were made to synthesize, isolate, characterize, identify and quantify the unknown impurity of RRT 0.66 .

\section{Materials and Methods}

Manufacturing process of sertraline unknown impurity at RRT 0.66

Stage- I: Preparation of 4-(4-chlorophenyl)-3,4dihydronaphthalen-1(2H)-one:

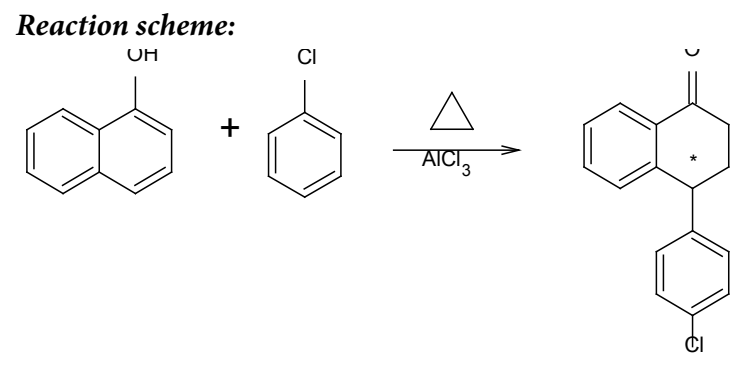<smiles>CN[C@H]1CC[C@H](c2ccc(Cl)c(Cl)c2)c2ccccc21</smiles>

Figure 1: Sertraline hydrochloride structure.

a-Naphthol Chlorobenzene 4 - (4-chlorophenyl) - 3,4dihydronaphthalen-1(2H)-one

Raw materials

\begin{tabular}{|c|c|c|c|c|c|c|}
\hline $\begin{array}{c}\text { S. } \\
\text { No. }\end{array}$ & Raw Material & Qty. & Unit & Mol. Wt. & Moles & $\begin{array}{c}\text { Molar } \\
\text { Ratio }\end{array}$ \\
\hline 1 & a-Naphthol & 50 & gm & 144.17 & 0.346 & 1 \\
\hline 2 & Chlorobenzene & 275 & $\mathrm{ml}$ & 112.56 & - & $5.5 \mathrm{~T}$ \\
\hline 3 & Aluminium chloride & 100 & $\mathrm{gm}$ & 133.34 & 0.74 & 2.2 \\
\hline 4 & Water & 500 & $\mathrm{ml}$ & 18 & - & $10 \mathrm{~T}$ \\
\hline
\end{tabular}

Process:

1. In a $500 \mathrm{ml}$ four neck $\mathrm{RBF}$ in oil bath with reflux condenser, charge $\alpha$-Naphthol (50 gm).

2. Add Chlorobenzene $(175 \mathrm{ml})$ and start stirring.

*Corresponding author: Ajit Anerao, R\&D Centre (API), Wanbury Ltd., EL-16, TTC Industrial Estate, Mahape, Navi Mumbai-400 710, Maharashtra, India, Tel: +912264570555/+917506734840; Fax: +912264570553; E-mail: ajit.anerao@wanbury.com

Received October 21, 2016; Accepted November 10, 2016; Published November 14, 2016

Citation: Anerao A, Telange V, Bondre N, John S, Dighe V (2016) Synthesis Characterization, Identification and Quantification of Sertraline Hydrochloride Related Impurities. Med Chem (Los Angeles) 6: 674-681. doi:10.4172/21610444.1000414

Copyright: ( 2016 Anerao A, et al. This is an open-access article distributed under the terms of the Creative Commons Attribution License, which permits unrestricted use, distribution, and reproduction in any medium, provided the original author and source are credited. 
Citation: Anerao A, Telange V, Bondre N, John S, Dighe V (2016) Synthesis, Characterization, Identification and Quantification of Sertraline Hydrochloride Related Impurities. Med Chem (Los Angeles) 6: 674-681. doi:10.4172/2161-0444.1000414

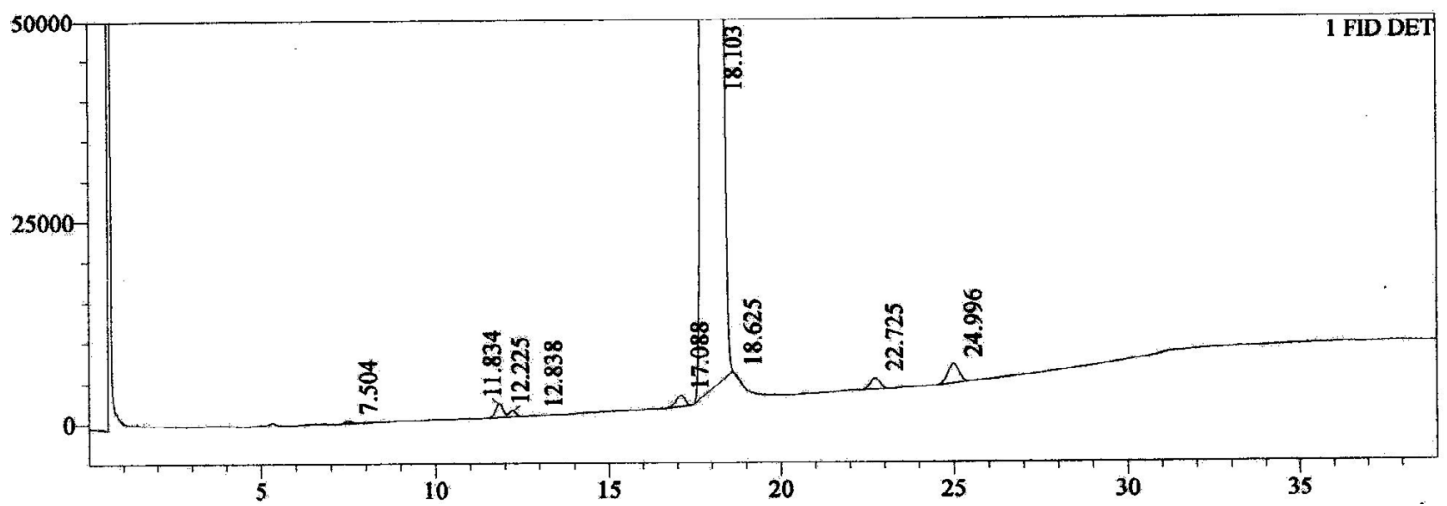

Figure 2: Sertraline hydrochloride commercial batch GC purity test solution chromatogram with unknown impurity at RRT 0.66 (retention time 11.834 minutes).

3. Charge Aluminium chloride (100 gm) lot wise at $25-30^{\circ} \mathrm{C}$ in 30 $\min$.

4. After complete addition of aluminium chloride, start heating to raise the temperature of reaction mass to $60-65^{\circ} \mathrm{C}$.

5. Maintain the temperature of the reaction mass to $60-65^{\circ} \mathrm{C}$ and check the progress of the reaction on TLC till complete conversion of a-Naphthol (Limit: $1.0 \%$ ). If not, then maintain further the reaction mass to $60-65^{\circ} \mathrm{C}$ till $\alpha-\mathrm{Naph}$ thol is in limit.

6. After completion of reaction, cool the reaction mass to $30-35^{\circ} \mathrm{C}$.

7. Add the reaction mass slowly into ice-cold water $(500 \mathrm{ml})$ with maintain temperature to $10-15^{\circ} \mathrm{C}$.

8. Separate out the organic and aqueous layer; wash aqueous layer with chlorobenzene (50 $\mathrm{ml} \times 2$ times) and send aqueous layer to ETP as waste.

9. Collect all organic layers and distill out chlorobenzene under vacuum at $70-75^{\circ} \mathrm{C}$ completely to get oily product. This product is mixture of 4-(4-chlorophenyl)-3,4-dihydronaphthalen-1(2H)-one and 4-(2-chlorophenyl)-3,4-dihydronaphthalen-1(2H)-one

\section{Observed Yield $=58$ gm}

\section{Theoretical Yield $=88.75 \mathrm{gm}$}

\section{Percentage Yield $=65.35 \%$}

10. These two products are separated by column chromatography [Silica bed (60-120 mesh) and mobile phase used is Ethyl acetate: Hexane $=2: 8]$

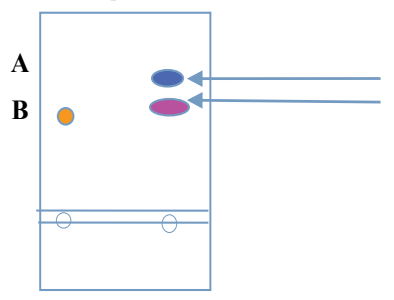

$\mathrm{A}=4$-(4-chlorophenyl)-3,4-dihydronaphthalen-1(2H)-one and

$\mathrm{B}=4$-(2-chlorophenyl)-3,4-dihydronaphthalen-1(2H)-one

11. Separate out 4-(4-chlorophenyl)-3,4-dihydronaphthalen$1(2 \mathrm{H})$-one with requisite amount and proceed further for next reduction step.
The experimental data is as follows:

\begin{tabular}{|c|c|c|c|c|c|}
\hline $\begin{array}{c}\text { S. } \\
\text { No }\end{array}$ & Batch number & Input & Output & $\begin{array}{c}\text { Reaction } \\
\text { condition }\end{array}$ & Result \\
\hline 1 & SET/40//270/45-B & $17 \mathrm{gm}$ & $2.5 \mathrm{gm}$ & $\begin{array}{c}\text { Column } \\
\text { purification }\end{array}$ & $\begin{array}{c}\text { Desired Unknown } \\
=99.39 \%\end{array}$ \\
\hline 2 & $\mathrm{SET} / 40 / / / 270 / 48$ & $15 \mathrm{gm}$ & $3 \mathrm{gm}$ & $\begin{array}{c}\text { Column } \\
\text { purification }\end{array}$ & $\begin{array}{c}\text { Desired Unknown } \\
=98.19 \%\end{array}$ \\
\hline
\end{tabular}

Stage-II: Preparation of 4-(4-chlorophenyl)-3,4dihydronaphthalen-1(2H)-ol

Reaction scheme:<smiles>CC1CCC(c2ccc(Cl)cc2)c2ccccc21</smiles>

4-(4-chlorophenyl)-3,4-dihydro- 4-(4-chlor ophenyl)-3,4dihydronaphthalen-1(2H)-ol naphthalen- $1(2 \mathrm{H})$-one naphthalen$1(2 \mathrm{H})$-one

\section{Raw materials}

\begin{tabular}{|c|c|c|c|c|c|c|}
\hline $\begin{array}{c}\text { S. } \\
\text { No. }\end{array}$ & Raw Material & Qty. & Unit & Mol. Wt. & Moles & $\begin{array}{c}\text { Molar } \\
\text { Ratio }\end{array}$ \\
\hline 1 & $\begin{array}{c}\text { 4-(4-chlorophenyl } \\
\text { )3,4-dihydronaphthalen-1(2H)- } \\
\text { one }\end{array}$ & 3 & gm & 256.72 & 0.0116 & 1 \\
\hline 2 & Methanol & 50 & $\mathrm{ml}$ & -- & -- & -- \\
\hline 3 & $\mathrm{NaBH}_{4}$ & 0.5 & $\mathrm{gm}$ & 37.83 & 0.0132 & 1.14 \\
\hline 4 & $\mathrm{MDC}$ & 150 & $\mathrm{ml}$ & -- & -- & -- \\
\hline
\end{tabular}

\section{Process}

1. Arrange $250 \mathrm{ml}$ four neck RBF in water bath and take methanol $(50 \mathrm{ml})$ into it.

2. Add 4-(4-chlorophenyl)-3,4-dihydronaphthalen-1(2H)-one (3.0 gm) and start stirring.

3. Cool the reaction mass to $10-15^{\circ} \mathrm{C}$.

4. Add $\mathrm{NaBH}_{4}(0.5 \mathrm{gm})$ to the reaction mass under stirring with 
Citation: Anerao A, Telange V, Bondre N, John S, Dighe V (2016) Synthesis, Characterization, Identification and Quantification of Sertraline Hydrochloride Related Impurities. Med Chem (Los Angeles) 6: 674-681. doi:10.4172/2161-0444.1000414

maintaining temperature of the reaction mass at $10-15^{\circ} \mathrm{C}$.

5. Maintain the reaction mass $2 \mathrm{hr}$ at $10-15^{\circ} \mathrm{C}$ and check for the complete conversion of 4-(4-chlorophenyl)-3,4-dihydronaphthalen$1(2 \mathrm{H})$-one on TLC (Limit: NMT1.0\%). If not, then add $\mathrm{NaBH}_{4}(0.1 \mathrm{gm})$ and check for completion.

6. After completion of reaction, distill out methanol from the reaction mass completely.

7. Add water $(50 \mathrm{ml})$ and stir the reaction mass at $30-35^{\circ} \mathrm{C}$.

8. Extract the compound with MDC (50 $\mathrm{ml} \times 3$ Times) and separate the organic MDC layer.

9. Collect all organic MDC layer and wash with water $(25 \mathrm{ml})$. Separate out the organic layer and distill out MDC completely at 40$45^{\circ} \mathrm{C}$.

10. Apply vacuum to remove MDC completely to get oil as 4-(4-chlorophenyl)-3,4-dihydronaphthalen-1(2H)-ol.

\section{Observed Yield $=2.6 \mathrm{gm}$}

Theoretical Yield $=3.02 \mathrm{gm}$

\section{Percentage Yield $=86.09 \%$}

11. This product is a mixture of following isomers
$(1 S, 4 S)$<smiles>CC1CCC(c2ccc(Cl)cc2)c2ccccc21</smiles><smiles>[CH][C@H]1CC[C@H](c2ccc(Cl)cc2)c2ccccc21</smiles>

$(1 \mathrm{R}, 4 \mathrm{R})$<smiles>C[C@@H]1CC[C@H](c2ccc(Cl)cc2)c2ccccc21</smiles>

$(1 \mathrm{~S}, 4 \mathrm{R})$

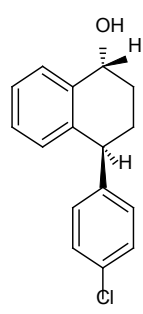

$(1 \mathrm{R}, 4 \mathrm{~S})$
The experimental data is as follows:

\begin{tabular}{|c|c|c|c|c|c|}
\hline $\begin{array}{c}\text { S. } \\
\text { No }\end{array}$ & Batch Number & Input & Output & $\begin{array}{c}\text { Reaction } \\
\text { condition }\end{array}$ & Result \\
\hline 1 & $\mathrm{SET} / 40 / \mathrm{II} / 270 / 46$ & $\begin{array}{c}1.2 \\
\mathrm{gm}\end{array}$ & $0.8 \mathrm{gm}$ & $\begin{array}{c}\text { Reduction in } \\
\mathrm{NaBH}_{4}\end{array}$ & $\begin{array}{c}\mathrm{RT}-11.98=51.15 \%, \\
\mathrm{RT}-12.33=47.58 \%\end{array}$ \\
\hline 2 & $\mathrm{SET} / 40 / \mathrm{II} / 270 / 49$ & $3 \mathrm{gm}$ & $3 \mathrm{gm}$ & $\begin{array}{c}\text { Reduction in } \\
\mathrm{NaBH}_{4}\end{array}$ & $\begin{array}{c}\mathrm{RT}-11.99=50.59 \%, \\
\mathrm{RT}-12.33=49.23 \%\end{array}$ \\
\hline
\end{tabular}

\section{Characterization data}<smiles>OC(O)C(=Cc1ccccc1)c1ccccc1</smiles>

${ }^{1} \mathrm{H}-\mathrm{NMR}$ spectra:
Instrument: Bruker NMR with $400 \mathrm{MHz}$

Solvent: DMSO- $\mathrm{d}_{6}$

Interpretation data

\begin{tabular}{|c|c|c|}
\hline $\begin{array}{c}\text { Chemical Shift Observed } \\
(\mathbf{p p m})\end{array}$ & Details & Protons \\
\hline$\delta 1.7078-\delta 1.8670$ & Multiplet, $2 \mathrm{H}$ & $-\mathrm{CH}_{2}$ - group protons $(\mathrm{f})^{*}$ \\
\hline$\delta 1.9724-\delta 2.0898$ & Multiplet, $2 \mathrm{H}$ & $-\mathrm{CH}_{2}-$ group protons $(\mathrm{g})^{*}$ \\
\hline$\delta 4.4735-\delta 4.5746$ & Triplet, $1 \mathrm{H}$ & $>\mathrm{CH}$ - group proton $(\mathrm{e})^{*}$ \\
\hline$\delta 4.6395-\delta 4.7354$ & Multiplet, $1 \mathrm{H}$ & $>\mathrm{CH}$ - group proton $(\mathrm{h})^{*}$ \\
\hline$\delta 5.2692-\delta 5.2887$ & Singlet, $1 \mathrm{H}$ & $\begin{array}{c}-\mathrm{OH} \text { group proton }(\mathrm{i})\left(\mathrm{D}_{2} \mathrm{O}-\right. \\
\text { Exchangeable })^{*}\end{array}$ \\
\hline$\delta 6.6400-\delta 7.5387$ & Multiplet, $8 \mathrm{H}$ & Aromatic proton $(\mathrm{a}, \mathrm{b}, \mathrm{c}, \mathrm{d}, \mathrm{j}, \mathrm{k}, \mathrm{I}, \mathrm{m})^{*}$ \\
\hline Total & 15 Protons & \\
\hline
\end{tabular}

"Note: All the Protons counts are observed in double due to the presence of distereomers.

\section{${ }^{13} \mathrm{C}-\mathrm{NMR}$ spectra}

Instrument: Bruker NMR with $400 \mathrm{MHz}$

Solvent: DMSO- $\mathrm{d}_{6}$

\section{Interpretation data}

\begin{tabular}{|c|c|}
\hline Chemical Shift Observed $\mathbf{( p p m )}$ & Carbons \\
\hline $26.51-27.46$ & $\mathrm{C}-14^{*}$ \\
\hline $29.78-31.03$ & $\mathrm{C}-15^{*}$ \\
\hline $41.47-42.07$ & $\mathrm{C}-13^{*}$ \\
\hline $66.69-66.95$ & $\mathrm{C}-16^{*}$ \\
\hline $126.59-126.70$ & $\mathrm{C}-7^{*}$ \\
\hline $127.37-127.71$ & $\mathrm{C}-10^{*}$ \\
\hline $128.30-128.35$ & $\mathrm{C}-8^{*}$ \\
\hline 128.43 & $\mathrm{C}-9$ \\
\hline $129.10-129.31$ & $\mathrm{C}-5$ and C-3 \\
\hline $129.63-129.85$ & $\mathrm{C}-2$ \\
\hline $131.06-131.32$ & $\mathrm{C}-6$ \\
\hline 138.33 & $\mathrm{C}-4$ \\
\hline $141.32-141.88$ & $\mathrm{C}-11$ \\
\hline Total & $\mathrm{C}-1$ \\
\hline
\end{tabular}

"Note: The presence of two Carbon Signals for each of the carbon indicates the presence of distereomers.

IR spectra

Instrument: Perkin Elmer

\begin{tabular}{|c|c|}
\hline Functional group & Characteristic absorption(s) $\mathbf{c m}^{-1}$ \\
\hline$-\mathrm{C}-\mathrm{OH}$ stretch & $3377.74 \mathrm{~cm}^{-1}$ \\
\hline $\mathrm{Ar}-\mathrm{Cl}$ stretch & $738.93 \mathrm{~cm}^{-1}$ \\
\hline
\end{tabular}

\section{Mass spectra}

Molecular ion peak observed as $(\mathrm{M}+\mathrm{H})=\mathbf{2 5 8 . 0}, \mathbf{2 5 9 . 1}, \mathbf{2 6 0 . 1}$

The above characterization $\left({ }^{1} \mathrm{H}\right.$ and ${ }^{13} \mathrm{C}$ NMR) and GC purity study was carried out using crude material batch No. SET/40/II/270/49. On basis of above study, it can be concluded that the unknown impurity at $R R T=0.66$ may be a mixture of four isomers [ $(R, R),(S, S),(R, S)$ and $(\mathrm{S}, \mathrm{R})]$ of 4-(4-chlorophenyl)-3,4-dihydronaphthalen-1(2H)-ol. 
Citation: Anerao A, Telange V, Bondre N, John S, Dighe V (2016) Synthesis, Characterization, Identification and Quantification of Sertraline Hydrochloride Related Impurities. Med Chem (Los Angeles) 6: 674-681. doi:10.4172/2161-0444.1000414

In GC purity of crude material batch No. SET/40/II/270/49 split peak was observed at RRT 0.66 so further study is carried out for separation and isolation of two peaks by HPLC. After few trials both peaks were separated by HPLC in batch No. SET/40/II/270/49. The first peak is eluting at retention time 27.7 minutes of purity $45.69 \%$ and second peak at 32.9 minutes of purity $54.19 \%$. The method was developed suitable for Liquid Chromatography-Mass Spectrometry (LCMS) study and mass of both peaks are determined. The mass of both peaks is observed same.

\section{LCMS spectra}

\section{Instrument: LCMSD_ALS}

LCMS chromatogram and spectrum is attached in Figure 3.
Molecular ion peak observed in LCMS at RT=13.02 $\mathrm{min}$ is 257.92 . Molecular ion peak observed in LCMS at RT $=14.3 \mathrm{~min}$ is 257.76

Further for isolation of both peaks of batch No. SET/40/II/270/49 preparative HPLC Technique was used. After isolating both peaks HPLC purity of individual isomer was checked and found Isomer-I eluting at retention time 24.5 minutes purity is $98.29 \%$ and peak purity on PDA detector is passing. Second isomer eluting at retention time 28.9 minutes purity is $99.18 \%$ and peak purity on PDA detector is passing.

Isomer-I and Isomer-II both are separately spiked in the sertraline hydrochloride sample and injected in GC purity method. It is found that the area of unknown impurity at RRT 0.66 has been increased in

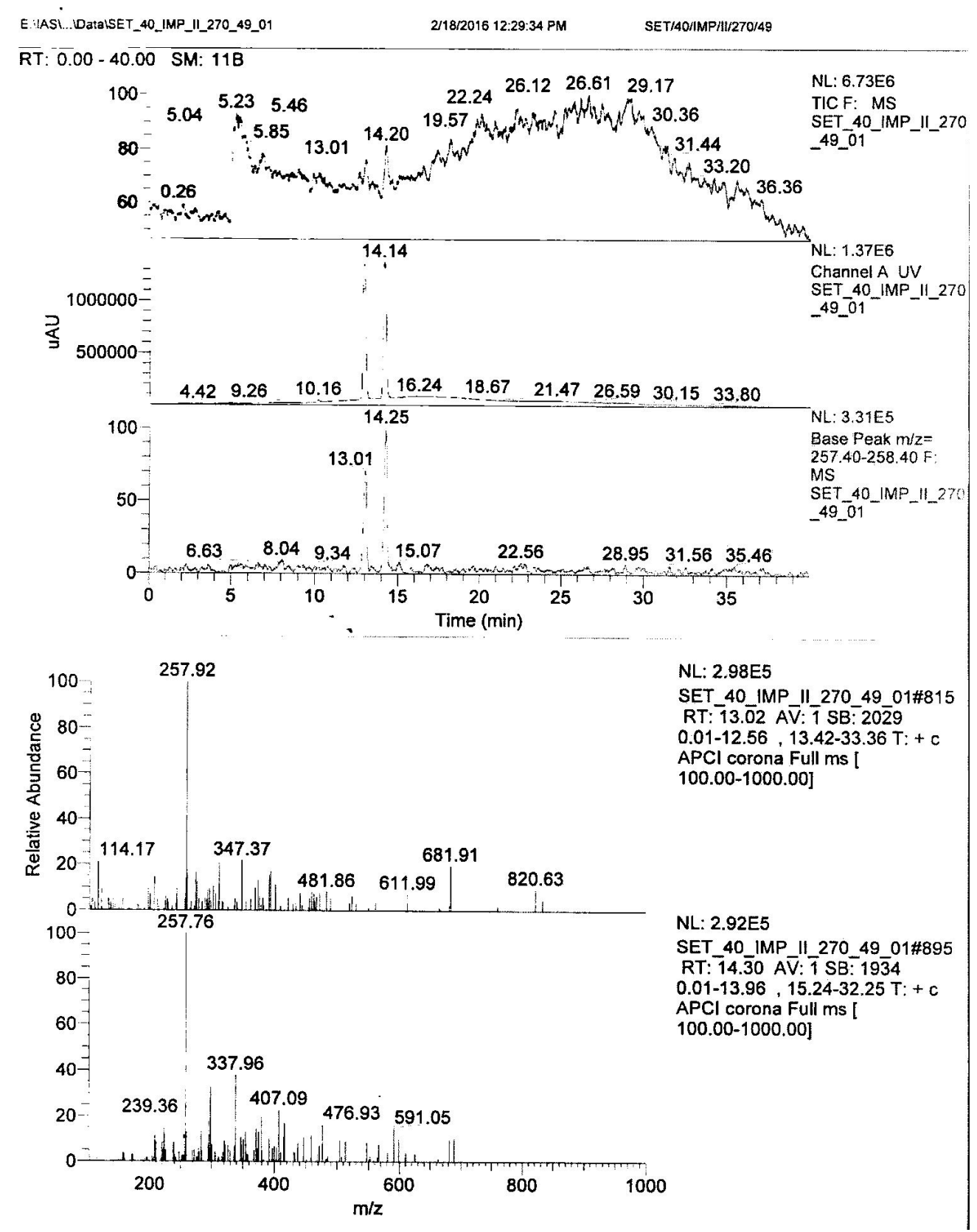

Figure 3: LCMS chromatogram and spectrum-isomer I at RT 13.02 minutes mass is 257.92 and isomer II at RT 14.30 minutes mass is 257.76 . 
Citation: Anerao A, Telange V, Bondre N, John S, Dighe V (2016) Synthesis, Characterization, Identification and Quantification of Sertraline Hydrochloride Related Impurities. Med Chem (Los Angeles) 6: 674-681. doi:10.4172/2161-0444.1000414

the sample spiked with Isomer-II. Isomer-II is exactly matching with the unknown impurity of RRT 0.66 . While Isomer-I is eluting closely after Isomer-II i.e., at RRT 0.67. For further confirmation GCMS was carried out and found that fragmentation pattern of unknown impurity at RRT 0.66 and Isomer-II is same.

From the above study, it can be concluded that the unknown impurity at RRT 0.66 in GC purity is Isomer-II. For quantification of unknown impurity at RRT 0.66 that is Isomer-II by GC the low load of Isomer-II i.e., $0.1 \%$ with respect to test concentration was injected in GC but it was found that the pure Isomer-II is thermally unstable and after degradation one degradant peak is eluting at retention time 7.1 minutes.

From above study, it is decided that unknown impurity in GC of RRT 0.66 to be disregarded in GC purity method and it has to be quantified by following HPLC method.

Reverse phase HPLC method of analysis for quantification of isomer I and isomer II of 4-(4-Chlorophenyl)-3,4Dihydronaphthalen-1(2h)-ol

Instrumentation and liquid chromatographic conditions: HPLC method was performed using a Shimadzu-2010 with UV detector and Lab Solution software. Separation was achieved with the mixture of Mobile Phase-A: Water: Acetonitrile: Methanol (500:450:50 v/v/v) and mobile phase-B: acetonitrile in gradient elution with timed programme $\mathrm{T}_{\min } / \mathrm{A}: \mathrm{B}: \mathrm{T}_{0} / 100: 00 ; \mathrm{T}_{20} / 100: 00 ; \mathrm{T}_{40} / 10: 90$; $\mathrm{T}_{60} / 10: 90 ; \mathrm{T}_{61} / 100: 00$ and $\mathrm{T}_{70} / 100: 00$ with flow rate $1.0 \mathrm{~mL} / \mathrm{min}$. The column temperature was maintained at $30^{\circ} \mathrm{C}$. Ultraviolet detection was performed at $210 \mathrm{~nm}$. Injection volume is $10 \mu \mathrm{L}$ and run time is 70.0 minutes. HPLC column is Cosmosil C18, $250 \mathrm{~mm}$ length, $4.6 \mathrm{~mm}$ internal diameter and $5 \mu \mathrm{m}$ particle size.

\section{Preparation of standard and sample solutions}

Diluent: Acetonitrile: Water (50:50 v/v)

Blank preparation: Same as diluent.

Standard stock solution: Weigh and transfer accurately about 3.0 $\mathrm{mg}$ each of Isomer-I and Isomer-2 Reference Standard in to $20 \mathrm{~mL}$ volumetric flask, add diluent, sonicate to dissolve and make up to the mark with diluent.

Standard solution: Transfer $1.0 \mathrm{~mL}$ Standard stock solution to 100
$\mathrm{mL}$ volumetric flask and diluted up to mark with diluent.

Test solution: Weigh and transfer accurately about $5.0 \mathrm{mg}$ of sample in to $5 \mathrm{~mL}$ volumetric flask, add diluent, sonicate to dissolve and make up to the mark with diluent

\section{Procedure}

Inject blank (diluent), Standard solution and Test solution in the chromatograph. The retention time of Isomer-I is about 24.5 minutes and Isomer-II is about 28.9 (Figures 4-6).

System suitability criteria: The system is suitable for analysis, if and only if

a) Resolution between Isomer-I and Isomer-II peak should be Not less than 3.0

b) \% RSD for areas of Isomer-I and Isomer-II in six replicate injections of standard solution should be not more than 5.0.

\section{Calculation}

Integrate the peaks of Isomer I and Isomer II in standard and test solution and calculate both isomers by following formula.

$$
\% \text { specified impurity }=\frac{\begin{array}{l}
\text { Area of isomer I or isomer II peak in Test solution } \times \\
\text { Conc of specified isomer in std. solution }(\mathrm{mg} / \mathrm{mL}) \times \mathrm{P} \times 100
\end{array}}{\begin{array}{l}
\text { Avg. area of isomer I or isomer II peak in std. solution } \times \\
\text { Conc of test solution }(\mathrm{mg} / \mathrm{mL}) \times 100
\end{array}}
$$

Where, $\mathrm{P}=$ Potency of specified isomer I or isomer II reference standard.

\section{Chiral HPLC method of separation of enantiomers of isomer I and isomer II of 4-(4-Chlorophenyl)-3,4-Dihydronaphthalen- 1(2h)-ol}

Instrumentation and liquid chromatographic conditions: HPLC method was performed using a Shimadzu-2010 with UV detector and Lab Solution software. Separation was achieved with the mixture of Mobile Phase- n-Hexane: Isopropyl alcohol: 1-Propanol: Diethylamine (490:0.5:2.5:0.5 v/v/v/v) in isocratic elution. The column temperature was maintained at $25^{\circ} \mathrm{C}$. Ultraviolet detection was performed at $275 \mathrm{~nm}$. Injection volume is $20 \mu \mathrm{L}$ and run time is 60.0 minutes. HPLC column is Chiralpak AD-H, $250 \mathrm{~mm}$ length, 4.6

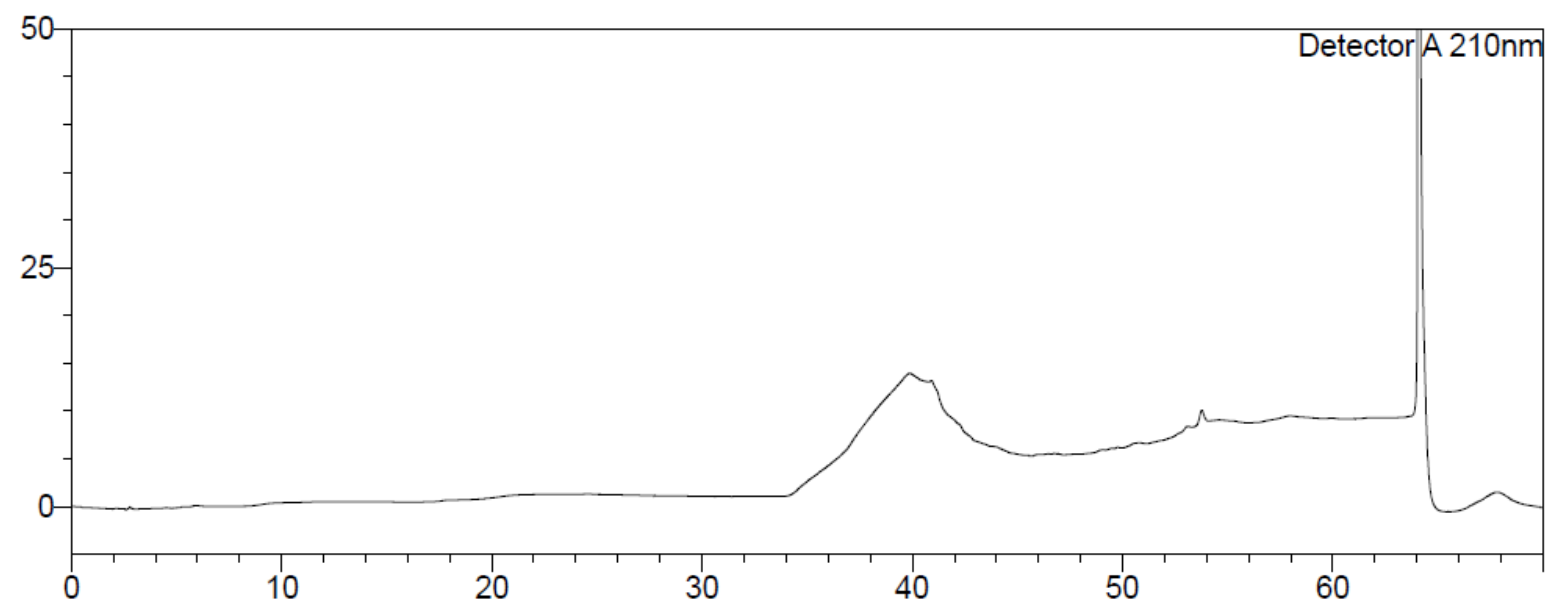

Figure 4: Blank chromatogram of RP-HPLC method for quantification of isomer I and isomer II. 
Citation: Anerao A, Telange V, Bondre N, John S, Dighe V (2016) Synthesis, Characterization, Identification and Quantification of Sertraline Hydrochloride Related Impurities. Med Chem (Los Angeles) 6: 674-681. doi:10.4172/2161-0444.1000414

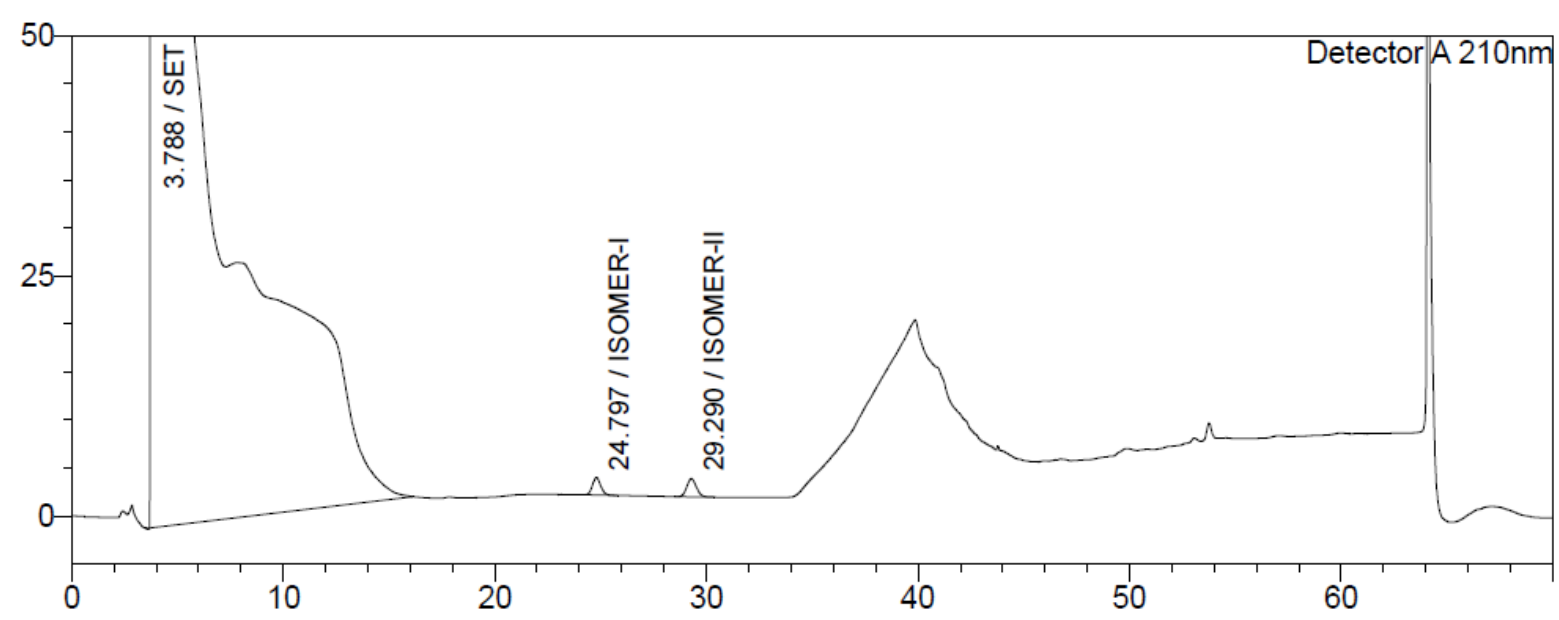

Figure 5: Chromatogram of RP-HPLC method for quantification of isomer I and isomer II standards spiked in sertraline hydrochloride sample.

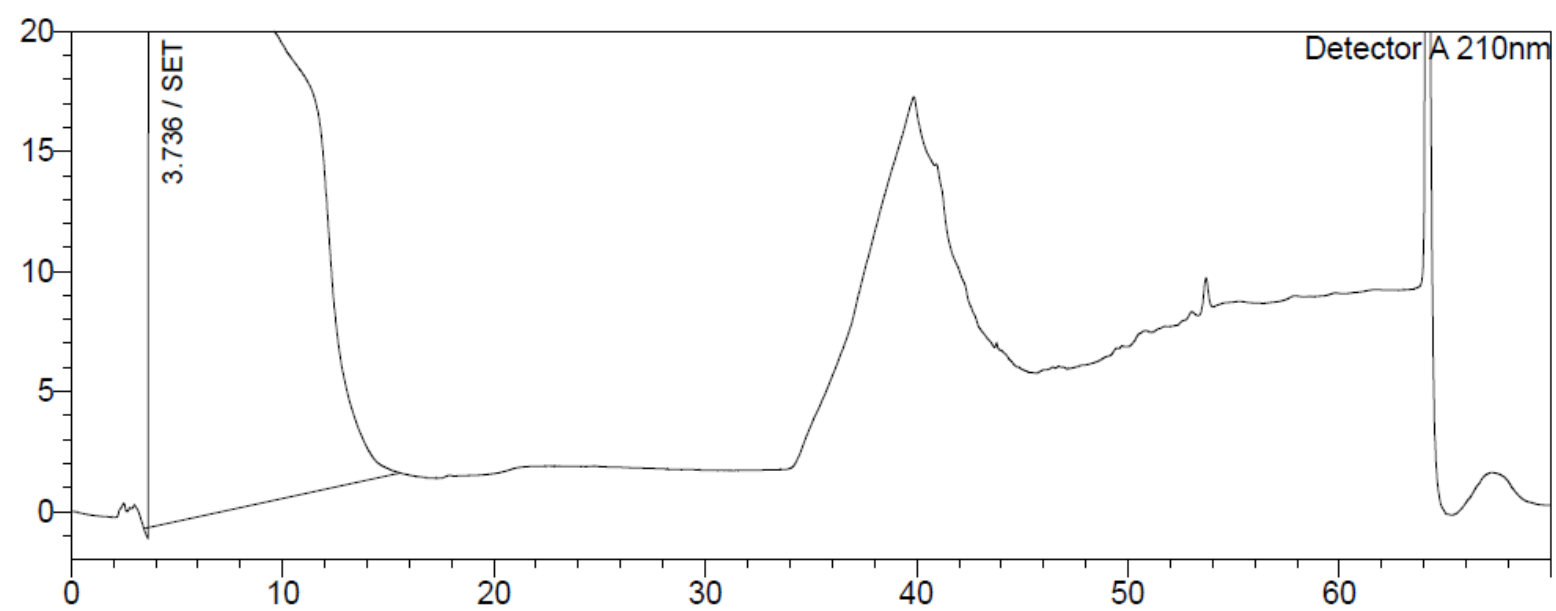

Figure 6: Test solution chromatogram of RP-HPLC method for quantification of isomer I and isomer II.

$\mathrm{mm}$ internal diameter and $5 \mu \mathrm{m}$ particle size.

\section{Preparation of standard and sample solutions}

Diluent: Same as mobile phase

Blank preparation: Same as diluent.

System suitability solution: Weigh and transfer accurately about $2.0 \mathrm{mg}$ each of Isomer-I and Isomer-2 Reference Standard in to $20 \mathrm{~mL}$ volumetric flask, add diluent, sonicate to dissolve and make up to the mark with diluent.

Test solution: Weigh and transfer accurately about $5.0 \mathrm{mg}$ of sample in to $5 \mathrm{~mL}$ volumetric flask, add diluent, sonicate to dissolve and make up to the mark with diluent

\section{Procedure}

Inject blank (diluent), system suitability solution and Test solution in the chromatograph. The retention time of Isomer-I peak-I is about 26.83 minutes, Isomer-II peak-I is about $31.24 \mathrm{~min}$, Isomer-II peak-II is about $34.75 \mathrm{~min}$ and Isomer-I peak-2 is about $41.94 \mathrm{~min}$ (Figures 7-9).

\section{System suitability criteria}

The system is suitable for analysis, if and only if, a) Resolution between closely eluting Isomer-II peak-1 and IsomerII peak- 2 should be Not less than 1.5 in system suitability solution.

\section{Results and Discussion}

Organic impurities of Sertraline hydrochloride are determined by gas chromatography method as per USP and EP monograph. In most of the commercial batches one major unknown impurity was observed at RRT 0.66 consistently about $0.15 \%$. This impurity is synthesized with help of chemical synthesis, by thin layer chromatography and by preparative HPLC.

During chemical synthesis, it had been observed that two impurities are formed which are eluting very closely in GC purity method at RRT 0.66 and 0.67 . This chemically synthesized crude material with mixture of two impurities was applied on preparative HPLC and two separate pure impurities are isolated. The purity of isomer I is $98.29 \%$ and isomer II is $99.18 \%$. Characterization of Isomer I and isomer II is done for structure elucidation with infra-red spectrometry (IR), NMR and mass.

\section{Characterization of Isolated Isomer I}

Accordingly, a first aspect of the present invention provides a compound Isomer I having chemical name (1S,4S)-4-(4-chlorophenyl)- 
Citation: Anerao A, Telange V, Bondre N, John S, Dighe V (2016) Synthesis, Characterization, Identification and Quantification of Sertraline Hydrochloride Related Impurities. Med Chem (Los Angeles) 6: 674-681. doi:10.4172/2161-0444.1000414

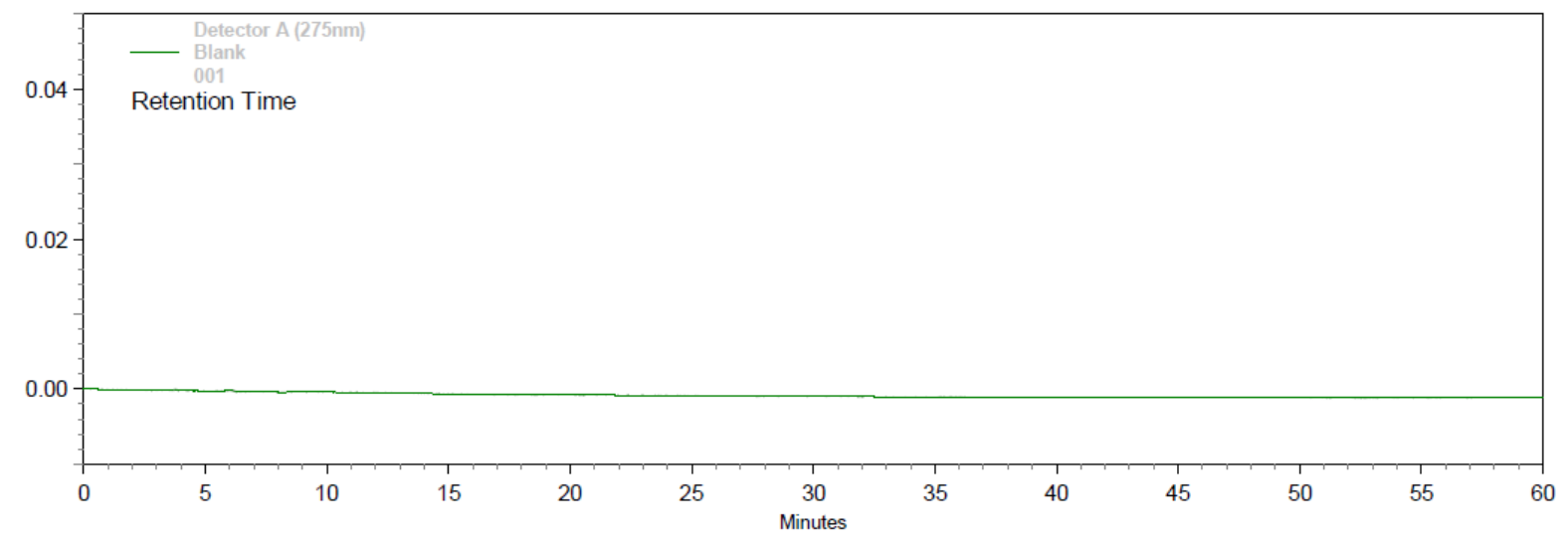

Figure 7: Blank chromatogram of chiral separation of enantiomers of isomer I and isomer II.

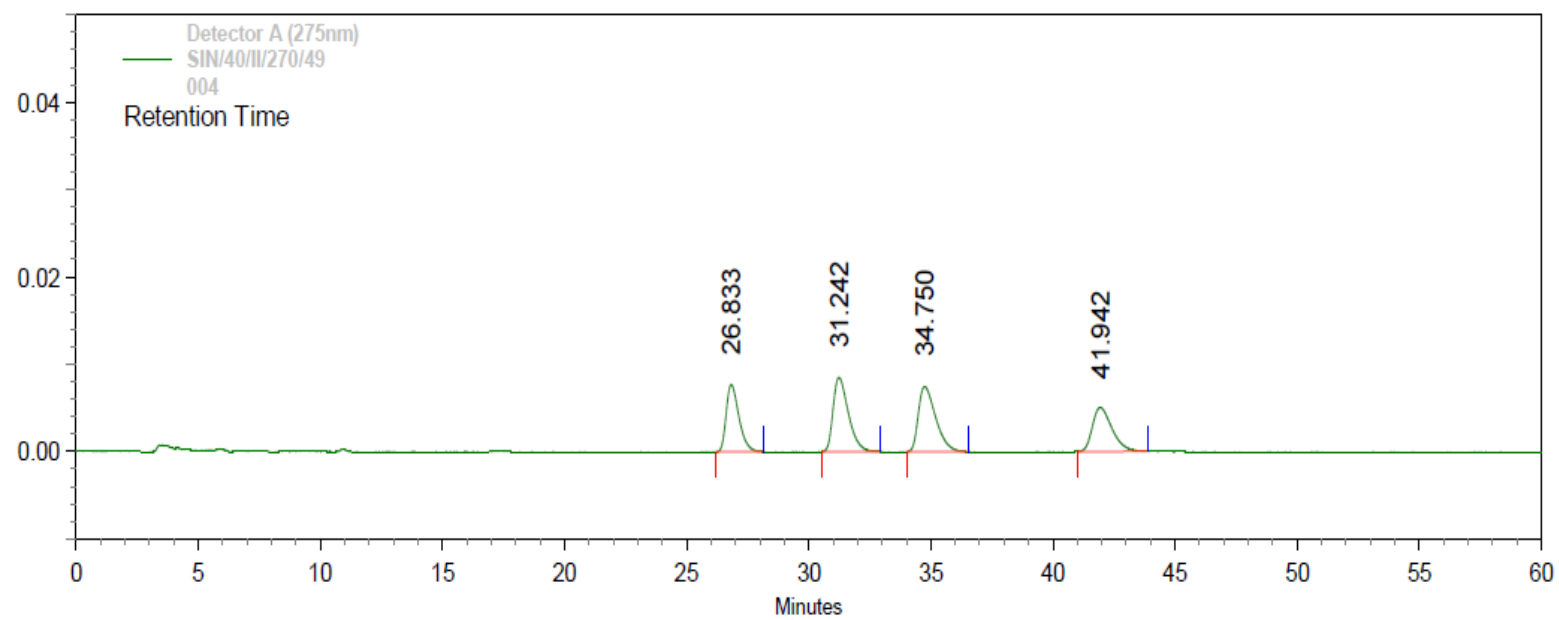

Figure 8: Standard solution chromatogram of chiral separation of enantiomers of isomer I and isomer II- The retention time of Isomer-I peak-I is about 26.83 minutes, Isomer-II peak-I is about 31.24 min, Isomer-II peak-II is about 34.75 min and Isomer-I peak-2 is about 41.94 minutes.

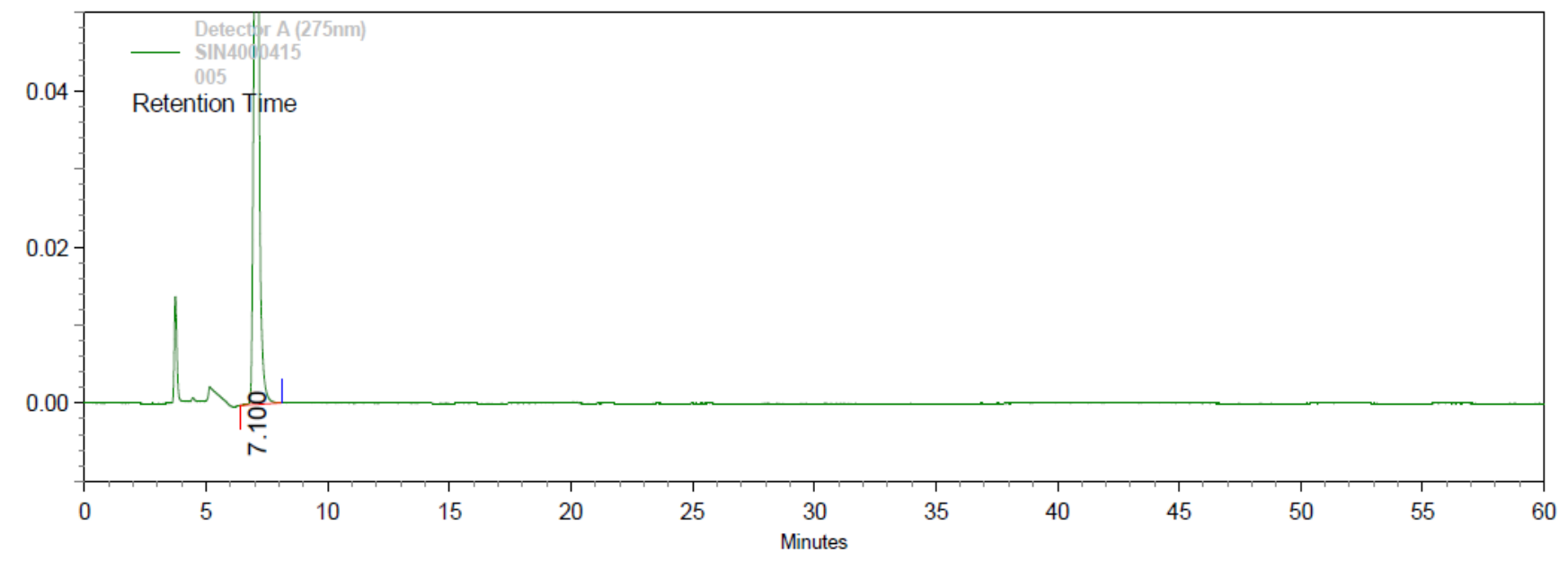

Figure 9: Test solution chromatogram of chiral separation of enantiomers of isomer I and isomer II. 
Citation: Anerao A, Telange V, Bondre N, John S, Dighe V (2016) Synthesis, Characterization, Identification and Quantification of Sertraline Hydrochloride Related Impurities. Med Chem (Los Angeles) 6: 674-681. doi:10.4172/2161-0444.1000414

1,2,3,4-tetrahydronaphthalen-1-ol and (1R,4R)-4-(4-chlorophenyl)1,2,3,4-tetrahydronaphthalen-1-ol<smiles>O[C@H]1CC[C@@H](c2ccc(Cl)cc2)c2ccccc2[C@H]1c1ccc(Cl)cc1</smiles>

Isomer I

MS (ESI positive ion) $\mathrm{m} / \mathrm{z} 258.0(\mathrm{M}+1)$

${ }^{1} \mathrm{H}-\mathrm{NMR}$ (DMSO, $\left.400 \mathrm{MHz}\right): \delta$ 1.68-1.89 (m, 4H), 1.99-2.51 (m, $4 \mathrm{H}), 4.47-4.57(\mathrm{t}, 2 \mathrm{H}), 4.64-4.65(\mathrm{~m}, 2 \mathrm{H}), 5.27$ and 6.54 (broad singlets, $\mathrm{D}_{2} \mathrm{O}$ Exchangeable, $\left.2 \mathrm{H}\right), 6.64-6.68(\mathrm{dd}, 2 \mathrm{H}), 6.81-6.90(\mathrm{dd}, 2 \mathrm{H}), 7.08$ $7.13(\mathrm{dd}, 2 \mathrm{H}), 7.19-7.46(\mathrm{~m}, 6 \mathrm{H}), 7.47-7.54(\mathrm{~m}, 4 \mathrm{H})$

${ }^{13} \mathrm{C}-\mathrm{NMR}$ (DMSO, $\left.400 \mathrm{MHz}\right): 26.50,27.45,29.77,31.03,41.46$, $42.06,66.69,66.94,126.59,126.70,127.38,127.58,127.72,128.31,128.37$, $128.43,129.10,129.23,129.32,129.64,129.86,131.07,131.32,133.33$, $138.24,138.36,141.33,141.88,144.09,144.33$.

\section{Characterization of Isolated Isomer II}

Accordingly, a second aspect of the present invention provides a compound Isomer II having chemical name (1S,4R)-4-(4chlorophenyl)-1,2,3,4-tetrahydronaphthalen-1-ol and (1R,4S)-4-(4chlorophenyl)-1,2,3,4-tetrahydronaphthalen-1-ol.<smiles>CC1C[CH+]C(c2ccc(Cl)cc2)c2ccccc21</smiles>

Isomer II

MS (ESI positive ion) $\mathrm{m} / \mathrm{z} 258.0(\mathrm{M}+1)$

${ }^{1} \mathrm{H}-\mathrm{NMR}$ (DMSO, $\left.400 \mathrm{MHz}\right): \delta$ 1.74-1.89 (m, 2H), 1.97-1.99 (m, $2 \mathrm{H}), 4.47-4.50(\mathrm{t}, 1 \mathrm{H}), 4.63-4.66(\mathrm{t}, 1 \mathrm{H}), 5.28$ and 6.54 (broad singlets, $\mathrm{D}_{2} \mathrm{O}$ Exchangeable, $\left.1 \mathrm{H}\right), 6.66-6.72(\mathrm{dd}, 1 \mathrm{H}), 6.88-6.90(\mathrm{~m}, 1 \mathrm{H}), 7.09-$ 7.16 (m, 2H), 7.20-7.42 (m, 3H), 7.47-7.49 (m, 2H)

${ }^{13} \mathrm{C}-\mathrm{NMR}$ (DMSO, $\left.400 \mathrm{MHz}\right): 26.51,29.77,41.45,66.69,126.70$, $127.57,128.31,129.23,129.31,129.64,131.32,133.33,138.36,141.32$, 144.33

Both isolated impurities isomer I and isomer II were separately spiked in to GC purity method and found that isomer II is exactly eluting at the retention time of the unknown impurity at RRT 0.66 .

In further studies, it was observed that the isolated impurities in their pure form are getting degraded in GC purity method because both are thermally unstable. So, for quantification of both impurities i.e., isomer I and isomer II of 4-(4-chlorophenyl)-3,4-dihydronaphthalen$1(2 \mathrm{H})$-ol HPLC method is developed.

Further for separation of enantiomers of both isomers chiral purity method was developed. In chiral purity method isomer I eluted as two enantiomers with the retention time of Isomer-I peak-I is about 26.83 minutes and Isomer-I peak- 2 is about $41.94 \mathrm{~min}$ while Isomer-II peak-I is about $31.24 \mathrm{~min}$, Isomer-II peak-II is about $34.75 \mathrm{~min}$ [9-12].

\section{Conclusion}

In conclusion, a process related impurity of sertraline hydrochloride produced according to the synthetic route explained above. Two impurities were identified, synthesized and characterized. Structural elucidations of both synthesized compounds were done by using proton NMR, IR and MS spectral data. Thus, the regulatory requirement was fulfilled by characterizing this impurity and the prepared impurity standard was used during analytical method development studies. Hence, the reported route of synthesis can be used for isolation of impurity and the analytical methods can be used for routine determination of both impurities in sertraline hydrochloride in quality control laboratories in the pharmaceutical industry.

\section{Acknowledgements}

Thanks to Mr. PV Pasupathy, President (API) and the management of Wanbury Limited for constant support.

\section{References}

1. Gobin V, Van Steendam K, Denys D, Deforce D (2014) Selective serotonin reuptake inhibitors as a novel class of immunosuppressants. Int Immunopharmacol 20: 148-156.

2. Ashbury JE, Lévesque LE, Beck PA, Aronson KJ (2012) Selective serotonin reuptake inhibitor (SSRI) antidepressants, prolactin and breast cancer. Front Oncol 2: 177.

3. Pohl RB, Wolkow RM, Clary CM (1998) Sertraline in the treatment of panic disorder: a double-blind multicenter trial. Am J Psychiatr 155: 1189-1195.

4. Katzelnick DI, Kobak KA, Greist JH, Jefferson JW, Mantle JM, et al. (1995) Sertraline for social phobia: a double-blind, placebo-controlled crossover study. Am J Psychiatr 152: 1368-1371.

5. Greist JH, Jefferson JW, Kobak KA, Chouinard G, DuBoff E, et al. (1995) A 1 year double-blind placebo-controlled fixed dose study of sertraline in the treatment of obsessive-compulsive disorder. Int Clin Psychopharmacol 10: 5766.

6. Ventimiglia J, Kalali AH (2010) Generic penetration in the retail antidepressant market. Psychiatry (Edgmont) 7: 9-11.

7. The United State Pharmacopoeia (2016) Sertraline Hydrochloride Monograph 3: 5831-5833.

8. European Pharmacopoeia (2011) Sertraline Hydrochloride Monograph 1705 3: $3210-3212$.

9. ICH (2006) Impurities in New Drug Substances Q3A (R2). International conference on harmonization of Technical Requirements for Registration of Pharmaceuticals for Human Use.

10. Rogowsky D, Marr M, Long G, Moore C (1994) Determination of sertraline and desmethylsertraline in human serum using copolymeric bonded-phase extraction, liquid chromatography and gas chromatography-mass spectrometry. J Chromatogr B Biomed Sci Appl 655: 138-141.

11. Kim KM, Jung BH, Choi MH, Woo JS, Paeng KJ, et al. (2002) Rapid and sensitive determination of sertraline in human plasma using gas chromatography-mass spectrometry. J Chromatogr B 769: 333-339.

12. Tournel G, Houdret N, Hedouin V, Deveaux M, Gosset D, et al. (2001) Highperformance liquid chromatographic method to screen and quantitate seven selective serotonin reuptake inhibitors in human serum. J Chromatogr B Biomed Sci Appl 761: 147-158. 